\title{
Comparison of high-frequency jet ventilation to conventional ventilation in adults with respiratory distress syndrome
}

\author{
L. Holzapfel, D. Robert, F. Perrin, P. Gaussorgues and D. P. Giudicelli \\ Service de Réanimation Médicale, Hôpital de la Croix Rousse, Lyon and CEMI, Inserm, Bron, France
}

Received: 15 June 1985; accepted: 28 June 1986

\begin{abstract}
Sixteen patients with acute respiratory failure (ARF) were studied. In group I (12 patients, 15 explorations) patients were treated with continuous positive pressure ventilation (CPPV) during conventional ventilation $(\mathrm{CV})$, pulmonary lesions $(\mathrm{PL})$ were severe $\left(\dot{\mathrm{Q}}_{\mathrm{sp}} / \dot{\mathrm{Q}}_{\mathrm{t}}=0.24 \pm 0.16\right.$ with $\mathrm{PEEP}=14 \pm 7 \mathrm{~cm}$ $\mathrm{H}_{2} \mathrm{O}$ ) and high-frequency jet ventilation (HFJV) was performed without spontaneous ventilation (SV). In group II (5 patients, 12 explorations) patients were treated with intermittent mandatory ventilation (IMV) during CV, PL were moderate $\left(\dot{\mathrm{Q}}_{\mathrm{sp}} / \dot{\mathrm{Q}}_{\mathrm{t}}=0.13 \pm 0.05\right.$ with $\mathrm{PEEP}=8 \pm 3 \mathrm{~cm} \mathrm{H}_{2} \mathrm{O}$ ) and $\mathrm{HFJV}$ was performed with SV. In both groups, frequency was $120 \mathrm{c} / \mathrm{mn}$ and $\mathrm{I}: \mathrm{E}$ ratio $=1: 2$. The cannula size, the driving pressure and the PEEP (water column) were progressively adapted to obtain the same blood gases as those observed during $\mathrm{CV}, \mathrm{FIO}_{2}$ being the same. Results on HFJV were compared to $\mathrm{CV}$. In both groups there were no differences between $\mathrm{PaCO}_{2}$, $\mathrm{PaO}_{2}, \mathrm{FIO}_{2}, \dot{\mathrm{Q}}_{\mathrm{sp}} / \dot{\mathrm{Q}}_{\mathrm{t}}$ during CV and HFJV. In group I peak airway pressure (PAWP), mean artery pressure (MAP), heart rate (HR), transmural mean pulmonary and wedge pressure $\left(\mathrm{MPAP}_{\mathrm{tm}}, \mathrm{PWP}_{\mathrm{tm}}\right)$ were not different. Mean airway pressure (MAWP), PEEP and pleural pressure (PP) were higher, cardiac index $(\mathrm{CI})$ was lower. In group II, PP, CI, MAP, HR, MPAP ${ }_{\text {tm }}$, MPWP $_{t m}$ were not different. PAWP was lower, MAWP and PEEP were higher. We conclude that during HFJV it is possible to obtain the same blood gas as during $\mathrm{CV}$, but HFJV without CV may not be indicated in patients with severe PL, because circulatory impairment is higher.
\end{abstract}

Key words: High-frequency jet ventilation - Acute respiratory failure - Positive end expiratory pressure - Assisted ventilation - Spontaneous ventilation Broncho-pleural fistula
Mechanical ventilation with positive end expiratory pressure (PEEP) improves gas exchange in the majority of patients with acute respiratory failure (ARF). This beneficial effect is, however, often associated with cardiac depression and barotrauma. High frequency ventilation (HFV) has been used since 1968 to maintain adequate gas exchange during tracheal surgery; it was then used for respiratory support in ARF. Adequate alveolar ventilation is achieved with very low peak and mean airway pressures, and circulatory impairment and barotrauma are less than with conventional ventilation (CV) [1-4].

High-frequency jet ventilation (HFJV) is one of many techniques that have been used and is characterized by the delivery of short rapid bursts (jets) of gas into the airway through a cannula. It was first employed by Carlon and Klain [2] in patients with airway disruption. Since this initial report there has been much interest in the use of HFJV for acute ventilatory failure. Unfortunately HFJV and CV have been compared in only a few prospective randomized studies of homogeneous patient populations [5-7].

\section{Material and methods}

\section{Clinical series}

Sixteen patients were studied (Table 1). All were previously healthy and fulfilled the ARDS criteria [8]. Five patients had broncho-pleural fistula. The study was performed after informed consent of the patients. Some patients were studied several times.

\section{Procedure}

Airway pressure was measured with a saline-filled catheter advanced into the endotracheal tube $10 \mathrm{~cm}$ distal to the tip of the injector cannula. Intrathoracic 
Table 1. Patients with acute respiratory failure. Interval from onset of ARDS to exploration with an asterisk corresponds to patients who were on IMV and without asterisk to patients who were on CPPV

\begin{tabular}{|c|c|c|c|c|c|c|}
\hline No. & Age & Sex & Diagnosis & Outcome & $\begin{array}{l}\text { Interval onset } \\
\text { ARDS to ex- } \\
\text { ploration (days) }\end{array}$ & Airleaks \\
\hline 1 & 70 & M & Legionaires'disease & $\mathrm{D}$ & $1-3-7$ & 0 \\
\hline 2 & 76 & $\mathrm{~F}$ & Mediastinitis & $\mathrm{S}$ & 5 & 0 \\
\hline 3 & 70 & $\mathrm{~F}$ & Pneumocystis carinii pneumonia & $\mathrm{D}$ & 3 & + \\
\hline 4 & 37 & M & Pneumococcal pneumonia & $\mathrm{D}$ & 1 & 0 \\
\hline 5 & 33 & $\mathbf{F}$ & Aspiration & $\mathrm{S}$ & 16 & + \\
\hline 6 & 31 & M & Encephalitis + pneumonia & $\mathrm{S}$ & 4 & + \\
\hline 7 & 43 & $\mathrm{~F}$ & Pneumococcal pneumonia & $\mathrm{D}$ & 9 & 0 \\
\hline 8 & 13 & M & Post operative respiratory insufficiency & $\mathrm{S}$ & 1 & + \\
\hline 9 & 11 & $\mathrm{~F}$ & Meningitis + pneumonia & $\mathrm{S}$ & 7 & 0 \\
\hline 10 & 27 & $\mathrm{~F}$ & Post operative respiratory insufficiency & $\mathrm{S}$ & $2-3$ & 0 \\
\hline 11 & 55 & M & E. Coli septicemia & $\mathrm{D}$ & 1 & 0 \\
\hline 12 & 71 & $\mathrm{M}$ & Mediastinitis & $\mathrm{D}$ & $7-8^{*}-9^{*}-10^{*}$ & 0 \\
\hline 13 & 30 & M & Post operative respiratory insufficiency & $\mathrm{S}$ & $4 *$ & 0 \\
\hline 14 & 29 & $\mathrm{~F}$ & Staphylococcal pneumonia & $\mathrm{S}$ & $18^{*}-20^{*}-21^{*}$ & + \\
\hline 15 & 58 & M & Post operative respiratory insufficiency & $\mathrm{S}$ & $14^{*}-15^{*}$ & 0 \\
\hline 16 & 58 & $\mathrm{~F}$ & Post operative respiratory insufficiency & $\mathrm{S}$ & $9^{*}-10^{*}-11^{*}$ & 0 \\
\hline
\end{tabular}

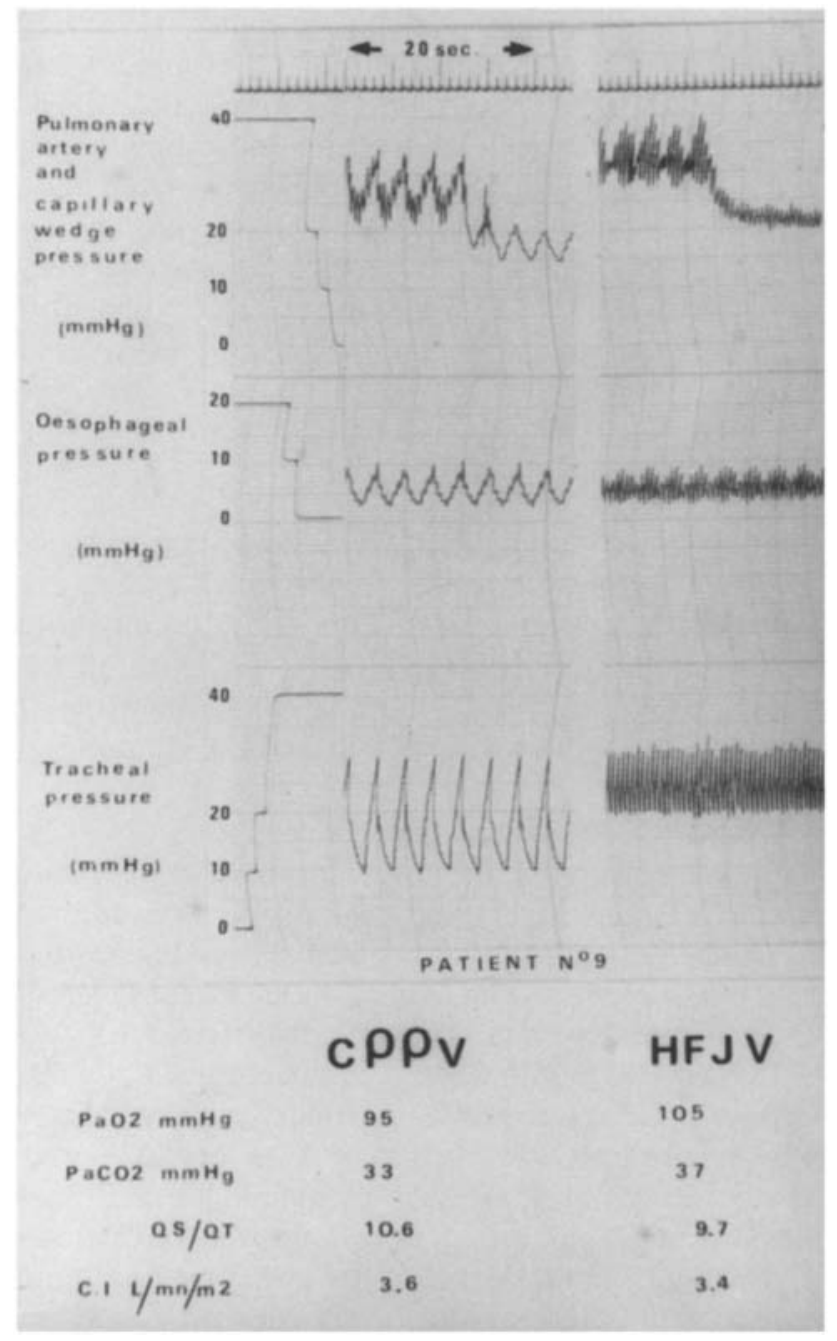

Fig. 1. Recordings and data obtained in a group I patient pressure was obtained from esophageal or pleural pressure measurements. Esophageal pressure was measured with the Milic Emili technic using an esophageal balloon; pleural pressure was measured with a saline filled catheter placed in the pleural cavity. All patients had a pulmonary arterial and a peripheral arterial catheter for blood pressure monitoring and blood gas analysis. Pressures were measured with a pressure transducer (Bentley Trantec) and recorded with a Gould polygraph. The frequency response of the airway pressure measurement system was $7 \mathrm{~Hz}$. Cardiac output was measured by a thermodilution technique (Roche Kontron). Paired samples of arterial and central mixed venous blood were analyzed for $\mathrm{PO}_{2}$, $\mathrm{PCO}_{2}, \mathrm{PH}$ (Corning 168) and hemoglobin; inspired gas was analysed for $\mathrm{O}_{2}$ (Beckmann OM11). $\dot{\mathrm{Q}}_{\mathrm{sp}} / \dot{\mathrm{Q}}_{\mathrm{t}}$ was calculated with the classic formula:

$\frac{\dot{\mathrm{Q}}_{\mathrm{sp}}}{\dot{\mathrm{Q}}_{\mathrm{t}}}=\frac{\mathrm{Cc}^{\prime} \mathrm{O}_{2}-\mathrm{CaO}_{2}}{\mathrm{Cc}^{\prime} \mathrm{O}_{2}-\mathrm{C} \overline{\mathrm{v}} \mathrm{O}_{2}}$

where $\mathrm{Cc}^{\prime} \mathrm{Ca}$ and $\mathrm{C} \overline{\mathrm{v}}$ are capillary, arterial and mixed venous blood oxygen contents. The aim of the study was to obtain the same blood gases during HFJV as those observed during $\mathrm{CV}, \mathrm{FIO}_{2}$ being the same.

Conventional ventilation was delivered by a Servo $\mathrm{C}$ or B ventilator (Siemens-Elema). Patients who demonstrated spontaneous ventilation were on IMV; frequency $(\mathrm{F})$, inspiratory/expiratory (I/E) ratio and tidal volume (TV) were set to obtain normocapnia with respiratory rate $<35$ cycle $/ \mathrm{min}$.

Patients who needed to be paralyzed (Pancuronium bromide) were on CPPV; $\mathrm{F}$ was $15 \mathrm{cycle} / \mathrm{min}, \mathrm{I} / \mathrm{E}$ ratio $1 / 1$, tidal volume 10 to $15 \mathrm{ml} \cdot \mathrm{kg}$. PEEP and 


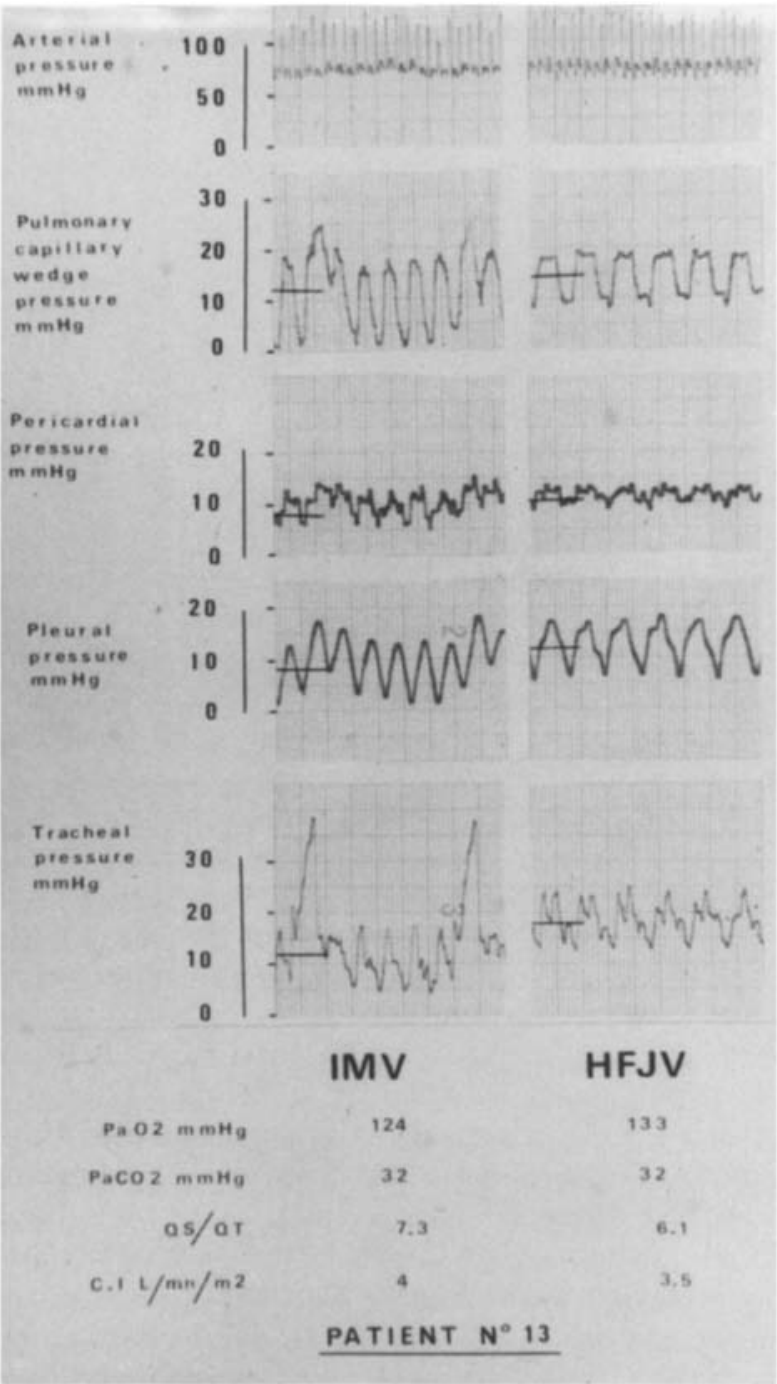

Fig. 2. Recordings and data obtained in a group II patient

$\mathrm{FIO}_{2}$ were set to obtain $\mathrm{PaO}_{2} \geqslant 60 \mathrm{mmHg}$. Some patients required either pressor or inotropic agents (Dopamine or Dobutamine) for cardiac support. In such cases, the dose rate of the agents was not changed during the period of investigation. Likewise, volume expansion was not performed acutely during the observation period.

HFJV was delivered by a jet ventilator corresponding to the description of Carlon [9]. It consists of a timer driving a solenoid valve; oxygen and air are supplied under a pressure of 50 PSIG from the central distribution system of the hospital and mixed to the desired oxygen concentration with a blender (veraflow air-oxygen blender). Through a compliant tube, gases are delivered to the proximal port of a solenoid valve. This valve is connected by an uncompliant tube to an injector cannula $1-1.6 \mathrm{~mm}$ in diameter (14-18 gauge). The cannula is positioned in the exact center of the proximal port of the endotracheal tube. To humidify the jet stream, saline is administered by an infusion pump to a catheter inserted in the endotracheal tube. Additional gases entrained by the jet drag action, are warmed and fully humidified before delivery into the airway by standard humidification systems. Additional and jet gases are delivered by the same blender at the same $\mathrm{FIO}_{2}$.

After obtaining data on $\mathrm{CV}$, patients were started on HFJV at the same $\mathrm{FIO}_{2}$ as during $\mathrm{CV}$. Frequency was $120 \mathrm{cycles} / \mathrm{min}$ and $\mathrm{I} / \mathrm{E}$ ratio $1 / 2$. The driving pressure and, if necessary the cannula size, were adjusted to obtain the same $\mathrm{PCO}_{2}$ as during $\mathrm{CV}$. Driving pressure ranged from 10-32 PSI. If $\mathrm{PaO}_{2}$ was lower, the PEEP level was progressively increased by placing a graduated water column in the expiratory circuit until the same $\mathrm{PaO}_{2}$ was obtained. Complete hemodynamic and blood gas data were obtained after 20 minutes equilibration. Patients were divided into two groups: Group I: 12 patients, 15 explorations; patients were on CPPV during CV. HFJV was performed without spontaneous ventilation (SV). Group II: 5 patients, 12 explorations; patients were on IMV during CV; HFJV was performed with SV. (Respiratory rate $35 \mathrm{cycle} / \mathrm{min}$ ). One patient was in group I and II. The mean interval between measurements during $\mathrm{CV}$ and HFJV was $105 \pm 51 \mathrm{~min}$. Airleak when present was subjectively quantified by several physicians during $\mathrm{CV}$ and HFJV. Statistical differences between data obtained during CV and HFJV were assessed with a Student's ' $t$ ' test for paired data.

\section{Results}

Data obtained during HFJV were compared to those obtained during CV and are presented in Table 2 (group I) and 3 (group II). Pulmonary lesions were severe in group $\mathrm{I}\left(\dot{\mathrm{Q}}_{\mathrm{sp}}\right) \dot{\mathrm{Q}}_{\mathrm{t}}=0.24 \pm 0.16$ with PEEP $14 \pm 7 \mathrm{~cm} \mathrm{H}_{2} \mathrm{O}$ during $\mathrm{CV}$ ) and moderate in group II $\left(\dot{\mathrm{Q}}_{\mathrm{sp}} / \dot{\mathrm{Q}}_{\mathrm{t}}=0.13 \pm 0.05\right.$ with PEEP $8 \pm 3 \mathrm{~cm} \mathrm{H} \mathrm{H}_{2} \mathrm{O}$ during $\mathrm{CV})$.

When HFJV without SV was compared to CPPV, $\mathrm{FIO}_{2}$ being the same (group I), mean airway pressure and PEEP were higher and peak airway pressure was not different. Intrathoracic pressure was higher and this might explain why cardiac index was decreased. Other hemodynamic data were not different.

When HFJV with SV was compared to IMV, $\mathrm{FIO}_{2}$ being the same (group II), mean airway pressure and PEEP were increased but peak airway pressures were lower. Intrathoracic pressure, cardiac index and other hemodynamic parameters were not different. In group I, 4 patients had airleaks; it was unchanged in 2 and increased in 2 . In group II, only 1 patient had a broncho-pleural fistula; it was not changed by HFJV. 
Tahle 2. Results of group I. Comparison of CPPV to HFJV without SV

\begin{tabular}{|c|c|c|c|}
\hline & CPPV & $\begin{array}{l}\text { HFJV } \\
\text { without SV }\end{array}$ & \\
\hline $\mathrm{PaO}_{2} \mathrm{mmHg}$ & $85 \pm 27$ & $85 \pm 29$ & ns \\
\hline $\mathrm{PaCO}_{2} \mathrm{mmHg}$ & $35 \pm 7$ & $35 \pm 7$ & ns \\
\hline $\mathrm{FIO}_{2} \%$ & $52 \pm 21$ & $52 \pm 21$ & $\mathrm{~ns}$ \\
\hline$\dot{\mathrm{Q}}_{\mathrm{sp}} / \dot{\mathrm{Q}}_{\mathrm{t}} \%$ & $24 \pm 16$ & $23.5 \pm 16$ & ns \\
\hline $\mathbf{F} \mathrm{c} / \mathrm{mn}$ & 0 & 0 & \\
\hline PAWP cm $\mathrm{H}_{2} \mathrm{O}$ & $40 \pm 13$ & $39 \pm 8$ & ns \\
\hline MAWP $\mathrm{cm} \mathrm{H}_{2} \mathrm{O}$ & $22 \pm 8$ & $30 \pm 7$ & $p \leqslant 0.05$ \\
\hline PEEP $\mathrm{cm} \mathrm{H} \mathrm{H}_{2} \mathrm{O}$ & $14 \pm 7$ & $23 \pm 7$ & $p \leqslant 0.05$ \\
\hline ITP $\mathrm{mmHg}$ & $10 \pm 6$ & $13 \pm 7$ & $p \leqslant 0.05$ \\
\hline MAP mmHg & $98 \pm 21$ & $100 \pm 23$ & ns \\
\hline $\mathrm{HR} \mathrm{c} / \mathrm{mn}$ & $113 \pm 25$ & $114 \pm 25$ & ns \\
\hline CI $\mathrm{L} / \mathrm{mn} / \mathrm{m}^{2}$ & $4.3 \pm 1.5$ & $3.8 \pm 1.5$ & $p \leqslant 0.05$ \\
\hline $\mathrm{MPAP}_{\mathrm{tm}} \mathrm{mmHg}$ & $24 \pm 9$ & $26 \pm 9$ & ns \\
\hline $\mathrm{PWP}_{\mathrm{tm}} \mathrm{mmHg}$ & $12 \pm 7$ & $11 \pm 8$ & ns \\
\hline
\end{tabular}

F: spontaneous respiratory rate; PAWP: peak airway pressure; MAWP: mean airway pressure; ITP: intrathoracic pressure; MAP: mean arterial pressure; HR: heart rate; $\mathrm{CI}$ : cardiac index; MPAP $_{\text {tm }}$ : mean pulmonary artery pressure (transmural pressure); PWP $_{t_{\mathrm{m}}}$ : Pulmonary wedge pressure (transmural). Numbers are means \pm standard deviation

\section{Discussion}

Gas exchanges on HFJV are determined by the cannula size, driving pressure, frequency, I/E ratio and the pressure added into the expiratory line (PEEP). We arbitrarily chose to keep constant frequency and I/E ratio and to allow variations of the three other parameters.

Patients were divided into two groups according to the possibility of spontaneous ventilation. Indeed when a patient exhibits spontaneous ventilation during mechanical ventilation, intrathoracic and tracheal pressures are decreased and cardiac depression and

Table 3. Results of group II. Comparison of IMV to HFJV with SV

\begin{tabular}{|c|c|c|c|}
\hline & IMV & HFJV with SV & \\
\hline $\mathrm{PaO}_{2} \mathrm{mmHg}$ & $92 \pm 20$ & $95 \pm 20$ & ns \\
\hline $\mathrm{PaCO}_{2} \mathrm{mmHg}$ & $35 \pm 5$ & $35 \pm 5$ & ns \\
\hline $\mathrm{FIO}_{2} \%$ & $39 \pm 3$ & $39 \pm 3$ & ns \\
\hline$\dot{\mathrm{Q}}_{\mathrm{sp}} / \dot{\mathrm{Q}}_{\mathrm{t}} \%$ & $13 \pm 5$ & $12 \pm 5$ & ns \\
\hline $\mathrm{F} \mathrm{c} / \mathrm{mn}$ & $33 \pm 8$ & $30 \pm 6$ & ns \\
\hline PAWP $\mathrm{cm} \mathrm{H}_{2} \mathrm{O}$ & $37 \pm 5$ & $28 \pm 6$ & $p \leqslant 0.05$ \\
\hline MAWP $\mathrm{cm} \mathrm{H} \mathrm{H}_{2} \mathrm{O}$ & $12 \pm 3$ & $18 \pm 5$ & $p \leqslant 0.05$ \\
\hline PEEP $\mathrm{cm} \mathrm{H}_{2} \mathrm{O}$ & $8 \pm 3$ & $13 \pm 4$ & $p \leqslant 0.05$ \\
\hline ITP $\mathrm{mmHg}$ & $6 \pm 5$ & $7 \pm 4$ & ns \\
\hline MAP mmHg & $82 \pm 13$ & $85 \pm 12$ & $\mathrm{~ns}$ \\
\hline $\mathrm{HR} \mathrm{c} / \mathrm{mn}$ & $92 \pm 18$ & $94 \pm 19$ & $\mathrm{~ns}$ \\
\hline $\mathrm{CI} \mathrm{L} / \mathrm{mn} / \mathrm{m}^{2}$ & $4.6 \pm 1.5$ & $4.1 \pm 1$ & ns \\
\hline $\mathrm{MPAP}_{\mathrm{tm}} \mathrm{mmHg}$ & $21 \pm 5$ & $23 \pm 6$ & ns \\
\hline $\mathrm{PWP}_{\mathrm{tm}} \mathrm{mmHg}$ & $10 \pm 5$ & $11.5 \pm 6$ & ns \\
\hline
\end{tabular}

barotrauma are less important. This was clearly demonstrated during IMV [10] but has been rarely studied during HFJV.

Waterson et al. [11] demonstrated that there were significant differences between airway pressures measured in the distal airway and those at the proximal end of the endotracheal tube. In our study airway pressure was recorded $10 \mathrm{~cm}$ distal to the tip of the injector cannula, as described by Carlon [3]. In group I patients, higher airway pressures during HFJV were associated to higher intrathoracic pressure, thus error due to airway location for the measurement of airway pressure can be eliminated.

Several studies over the past few years have compared HFJV to CV in terms of airway pressure, gas exchange and hemodynamics. In healthy dogs, Chiaranda [12] compared the two modes of ventilation at the same $\mathrm{PaCO}_{2}$ and PEEP levels; the results showed that HFJV ensured adequate gas exchange at lower peak and mean airway pressures and consequently reduced hemodynamic depression. In dogs with oleic acid-induced pulmonary edema, Shuster [13] made the same comparison; when $\mathrm{FIO}_{2}$ and level of PEEP were the same, $\mathrm{PaO}_{2}$ was lower and venous admixture higher with HFJV. However, due to the higher level of PEEP, venous admixture was lower with HFJV when comparisons were made at the same peak airway pressure. At each level of PEEP, cardiac and stroke indices were not different between the two methods of ventilation. In this dog model, HFJV does not seem to improve oxygenation. In fact, pulmonary shunt may increase if mean airway pressure is decreased when there are numerous alveoli with high critical opening pressures.

Rouby [14] has shown in 15 critically ill patients that HFJV induces a 'PEEP effect'; thus, pulmonary volume is higher during HFJV compared to CV. In our study, lung volume was not measured and one can suppose that resting lung volume was largely increased due to the higher level of PEEP used but also due to HFJV in itself; this can explain the marked decrease in cardiac index. The $\mathrm{PaO}_{2}$ was the same during HFJV and $\mathrm{CV}$ despite a probable higher lung volume during HFJV; this is in contradiction with studies in animal models of lung injury by saline lavage or oleic acid [15] where oxygenation during HFV was equivalent to that during $\mathrm{CV}$, provided that the mean lung volumes were identical in both conditions.

Many authors suggest that HFJV had some advantages compared to $\mathrm{CV}$; but they never proved this superiority; moreover their studies have always involved small numbers of patients [2, 16-18]. Carlon [3] described his clinical experience with 17 patients who could not be supported with conventional mechanical ventilation and were placed on HFJV. In all cases alveolar ventilation could be maintained within the 
desired range and hemodynamic function was unchanged. But in this study, data are insufficient to compare HFJV to CV.

Other authors compared these two methods of ventilation during the post-operative period. Sladen et al. [19] found that airway pressure was lower during HFJV, cardiac indices were not different, $\mathrm{PaO}_{2}$ decreased and $\dot{\mathrm{Q}}_{\mathrm{sp}} / \dot{\mathrm{Q}}_{\mathrm{t}}$ increased. The authors suggested that the increased venous admixture was due to small inspired gas volumes and they recommended initiating HFJV at $\mathrm{FIO}_{2}$ of 0.9 and PEEP of $5 \mathrm{~cm} \mathrm{H}_{2} \mathrm{O}$.

Only three studies have compared HFJV and CV in prospective randomised studies of patients with severe acute respiratory failure. Carlon et al. [7] compared HFJV without SV to CPPV in 12 preterm infants. Their results differed from ours: $\mathrm{PaO}_{2}$ was the same during the two modes of ventilation but peak and mean airway pressure were lower on HFJV. Shuster et al. [5] compared HFJV without SV to CPPV in 9 patients with acute respiratory failure: the results are consistent with ours: $\mathrm{PaO}_{2}$ was the same during the 2 modes of ventilation and mean airway pressure was higher (peak airway pressure was lower and PEEP the same). In conflict with a number of other clinical studies, they did not find that $\mathrm{PaO}_{2}$ was better during HFJV. Carlon et al. [6] in a large prospective randomised study compared the outcome of HFJV with $\mathrm{CV}$, for any form of respiratory insufficiency. They showed that in their population of 309 ARDS patients, survival, gas exchanges and complications were the same with the 2 methods of ventilation.

Early investigations on HFJV indicated that it was effective in patients with airway disruption $[2,3,17$, 20]. In these studies, adequate alveolar ventilation, which was not possible with $\mathrm{CV}$, was achieved by HFJV; airleaks were not decreased by HFJV: when present they remained constant. Only Pokora [21] found radiological evidence of decrease pulmonary air leaks in seven of nine neonates. In our study, 5 patients had a broncho-pleural fistula; similar gas exchanges were obtained on HFJV; mean airway pressure was higher and peak airway pressure unchanged. In two patients the airleak was increased, in 3 it was not changed.

Klain proposed HFJV in the weaning of ventilator dependant patients [22]; one advantage of this method of ventilation is that it can be superimposed on the patient's spontaneous breathing with excellent tolerance; the weaning process consists in decreasing progressively ventilatory support.

Other forms of high frequency ventilation were investigated: high frequency positive pressure ventilation (HFPPV) was developed by Sjostrand [4]; in a study of 12 patients with respiratory failure, HFPPV was compared to CV [23]. Cardiac index and oxygen trans- port were not affected by changes in ventilatory pattern. Marchak et al. [24] treated eight neonates with severe respiratory distress syndrome; oxygenation was better than during CPPV but this was associated with higher mean airway pressure.

\section{Conclusion}

Adequate gas exchanges can be achieved by HFJV without SV in patients with severe respiratory failure; airway pressure was higher than during CV. We did not establish that this method of ventilation was superior to CPPV and this is in agreement with other studies. When HFJV was performed with SV in patients with moderate respiratory failure, adequate gas exchanges were obtained, and peak airway pressure was lower than during IMV. This study suggests that HFJV may be an alternative method of ventilation in patients with moderate respiratory failure but may not be indicated in patients with severe respiratory failure.

Acknowledgements. The authors would like to thank D. Forest for technical collaboration and E. Henrique, S. Basset for typing the manuscript.

\section{References}

1. Klain M, Smith RB (1977) High frequency percutaneous transtracheal jet ventilation. Crit Care Med 5:280

2. Carlon GC, Ray C, Klain M (1980) High-frequency positive pressure ventilation in management of a patient with bronchopleural fistula. Anesthesiology 52:160

3. Carlon GC, Kahn RC, Howland WS (1981) Clinical experience with high frequency jet ventilation. Crit Care Med 9:1

4. Sjöstrand U (1980) High frequency positive pressure ventilation (HFPPV): a review. Crit Care Med 8:345

5. Schuster DP, Klain M, Snyder JV (1982) Comparison of high frequency jet ventilation to conventional ventilation during severe acute respiratory failure in humans. Crit Care Med 10:625

6. Carlon GC, Howland WS, Ray C (1983) High-frequency jet ventilation: a prospective randomized evaluation. Chest 8:551

7. Carlo WA, Chatburn RL, Martin RJ (1984) Decrease in airway pressure during high-frequency jet ventilation in infants with respiratory distress syndrome. Pediatrics 104:101

8. Pontoppidan H, Geffin B, Lowenstein E (1972) Acute respiratory failure in the adult. N Engl J Med 287:690

9. Carlon GC, Miodownik S, Ray C (1981) Technical aspects and clinical implications of high frequency jet ventilation with a solenoid valve. Crit Care Med 9:47

10. Kirby RR (1977) Intermittent mandatory ventilation in the neonate. Crit Care Med 5:18

11. Waterson CK, Militzer HW, Quan SF (1984) Airway pressure as a measure of gas exchange during high-frequency jet ventilation. Crit Care Med 12:742

12. Chiaranda M, Rubini A, Fiore G (1984) Hemodynamic effects of continuous positive-pressure ventilation and high-frequency jet ventilation with positive end-expiratory pressure in normal dogs. Crit Care Med 12:750 
13. Schuster DP, Snyder JV, Klain M (1982) Comparison of Venous admixture during high-frequency ventilation and conventional ventilation in oleic acid-induced pulmonary edema in dogs. Anesth Analg 61:735

14. Rouby JJ, Simonneau G, Benhamou D (1985) Factors influencing pulmonary volumes and $\mathrm{CO}_{2}$ elimination during high-frequency jet ventilation. Anesthesiology 63:473

15. Chang HK, Harf A (1984) High-frequency ventilation: a review. Respir Physiol 57:135

16. Schuster DP, Snyder JV, Klain M (1981) High-frequency jet ventilation during the treatment of acute fulminant pulmonary edema. Chest 6:682

17. Derderian SS, Rajagopal KR, Abbrecht PH (1982) High frequency positive pressure jet ventilation in bilateral bronchopleural fistula. Crit Care Med 10:119

18. Ashley M, Cameron AE, Slee IP (1983) High frequency jet ventilation - its use in respiratory insufficiency. Intensive Care Med 9:257

19. Sladen A, Guntupalli K, Klain M (1984) High-frequency jet ventilation versus intermittent positive-pressure ventilation. Crit Care Med 12:788
20. Mickell JJ, Doyle HJ (1983) Jet ventilation for air leak complicating 'adult' respiratory distress syndrome (ARDS) in infants. Pediatr Res 17:383

21. Pokora T, Bing D, Mammel M (1983) Neonatal high-frequency jet ventilation. Pediatrics 72:27

22. Klain M, Kalla R, Sladen A (1984) High-frequency jet ventilation in weaning the ventilator-dependent patient. Crit Care Med $12: 780$

23. Wattwil LM, Sjöstrand UH, Borg UR (1983) Comparative studies of IPPV and HFPPV with PEEP in critical care patients. I: a clinical evaluation. Crit Care Med 11:30

24. Marchak BE, Thompson WK, Duffty P (1981) Treatment of RDS by high-frequency oscillatory ventilation: a preliminary report. J Pediatr 99:287

Dr. L Holzapfel

Service de Réanimation

Centre Hospitalier

F-01012 Bourg en Bresse

France

\section{Announcements}

\section{International Congress on Intensive Care Medicine}

This congress will take place in Maastricht (The Netherlands) from 3-5 September 1987. It will be organised by the Nederlandse Vereniging voor Intensive Care Geneeskunde. For further information contact: International Congress on Intensive Care Medicine, c/o Department of General Surgery, Mrs. M. Frank-Roovers, Academic Hospital Maastricht, P.O. Box 1918, Maastricht, The Netherlands.

\section{4th Congress of Western Pacific Association of Critical Care Medicine}

This congress will be held from 7-9 September 1987, in Bali and will consist of: scientific programmes, organizational meetings, trade and pharmaceutical exhibitions, demonstrations, films and social programmes. Main topics: ICU development in Western Pacific Region; role of computer in ICU; cost benefit ratio in CCM in Western Pacific region; ethical problems in CCM; infection; nutrition for critically ill patients; respiratory distress syndrome (RDS); emergency medicine; current status of educational problems of CCM in Western Pacific Region. For further information contact: Indonesian Society for Critical Care Medicine, P.O. Box 123/Jat.jg Jakarta 13001, Jakarta, Indonesia.

\section{Eighth International Symposium on Intensive Care and Emergency Medicine}

This symposium will be held on 22-25 March 1988 in Brussels. For further information contact: International Symposium on Intensive Care and Emergency Medicine, Dr. Jean-Louis Vincent, Route de Lennik 808, B-1070 Bruxelles, Belgium.

\section{Emergency Medicine Training Programme}

In the Emergency Department of the University Hospitals of Leuven, Belgium, a training programme in Emergency Medicine was started on 1 August 1986. The training programme provides a certificate of special competence in Emergency Medicine and is offered to specialists and residents in training who have already finished an important part of their residency curriculum. The Emergency Department serves the totality of the Leuven University Hospitals (1600 beds) and provides a 24-bed unit for short-term hospitalization, including a 7-bed unit for critical care. The Emergency Medical System Service for the Leuven region is based in the Emergency Department. Training includes active participation in teaching and research, a.o. pre- and inhospital CPR study. For information, programme and application contact: $\mathrm{H}$. Delooz, MD, PhD, Chief Emergency Department, University Hospital Sint-Rafaël/Gasthuisberg, B-3000 Leuven, Belgium. 